\title{
Controversial And Challenging Concerns Regarding Status Of Saudi Preschool Teachers
}

\author{
Nahla Gahwaji, King Abdulaziz University, Saudi Arabia
}

\begin{abstract}
This article describes the geographical, religious, economical, cultural, and educational contexts as they not only influence the status of Saudi preschool teachers but also have shaped early childhood teaching career. It aims to capture and present teachers' subjective experiences as members of the profession through semi-structured interviews to assist in the conceptualization of effectiveness and professional development of teachers' roles and their status. This article focuses on preschool teachers' perceptions regarding their career and their individual evaluation of their work in contrast to the community that they serve, which created controversial concerns and challenges.
\end{abstract}

Keywords: Early Childhood Education; Preschool Teachers; Professional Development; Qualifications

\section{INTRODUCTION}

$\mathrm{t}$ is impossible to discuss the status of preschool teachers independent of the framework in which they exist because it is reflected in a different way in Saudi Arabia across various geographical, religious, economical, cultural, and educational contexts. The article describes these contexts as they not only influence the status of preschool teachers, but also have shaped early childhood professions and teaching careers and have created controversial and challenging concerns. Factors will be discussed that might influence perceptions of teachers' status, such as government initiatives or the portrayal of teachers in society.

The process of identifying the status of Saudi preschool teachers, particularly when considering other applications in different countries, presents a number of difficulties despite its short history and successful implementation. For example, there are no national statistics or data in the preschool provision that document teachers by qualifications, experiences, salaries, and so forth. Even defining preschool education from a community perspective can be difficult. Whom does it serve? Where is it offered? By whom is it designed/funded/administered? These are only a few of the questions that arise when seeking to interpret the status of preschool teachers in the Saudi community.

In summarizing the findings of their literature review on teacher motivation, Spear and others (2000) found that for undergraduates considering teaching, the most attractive aspect of the occupation was the chance to benefit society. In a large-scale project covering four countries (Australia, New Zealand, England, and the United States), Scott, Stone and Dinham (2001) used teachers' own words to explore both satisfiers and dissatisfiers in teaching. Satisfiers related to social contributions and personal growth. Teachers enjoyed working with children and assisting them; a feeling of professional efficacy was enjoyed when teaching children that enabled them to "make a difference".

A study of turnover in UK teachers (Smithers \& Robinson, 2004) suggested that although salary was often mentioned as a possible inducement to stay, it was rarely given as the key reason for leaving (workload was cited most often). Gerrard (2004) reported that beginning teachers viewed the amount of paperwork and administration they had encountered as the major downside to the job and returning teachers and heads of departments both mentioned workload as an aspect of the job they did not like. Also, Johnson and others (2005) added that the dissatisfaction with workload is not about the number of hours worked as such; it is the time spent on tasks imposed on teachers, recording in great deal everything that is planned and done- much of which is never read by anyone - rather than on teaching. 
Teachers' salaries are generally considered to be low in relation to their workload, which is indicative of a career with an enormous workforce, whose customers are children, whose workers are mostly women, and whose salaries are paid from children's fees or government funds. In addition to the relatively low salaries is the perception that teaching is a career within which advancement and remuneration for excellent performance is not possible. There are reports of inadequate and ad hoc forms of teacher appraisal and limited systems for supporting teachers who are less than effective in their work (Keller, 2003).

Research evidence indicates that public rankings of occupational hierarchies show that the category 'school teacher' tends to appear in the upper quartile of the range. On the other hand, 'preschool teachers' were ranked in the lower quartile of the range (Hodgkinson, 2003). This comparative analysis concluded that the status of preschool teachers is declining in the United States (US). Another concern is the lack of adequate numbers of qualified and sufficiently trained staff to implement appropriate, effective curriculum and assessment. In the US, turnover continues to exceed 30\% annually (Lombardi, 2003; Whitebook et al., 2001) and compensation for early childhood educators continues to be inadequate and inequitable (Bartley \& Sneed, 2004). The staff turnover rate is greatly affected by several program characteristics, including the adequacy of compensation.

If salaries rely on qualifications, the average teacher may have difficulty finding promising payment as the requirements for preschool teachers who work in private settings differ noticeably from the high qualifications in place for teachers in government-funded preschool centers. Public employment has been, and still is, very attractive for recent graduates due to high salaries and benefits, job security, and social status. Nevertheless, the number of public preschool centers throughout the country is relatively low as compared to private centers, which has made the private sector the chief employer for preschool teachers in Saudi Arabia. It can be concluded that with more women receiving education in schools and universities, the status of women in the region will continue to improve.

Data from international research suggests that preschool teachers are regarded as having lower status than other teachers in upper levels or subjects (OFSTED, 2003). In short, on paper, it has similar status, but in reality, it does not.

\section{PURPOSE AND METHODS}

The purpose of the study is to explore the concept of professionalism from a ground-up perspective to reconceptualize preschool teachers' status. In particular, the study aims to: 1) describe the geographical, religious, educational, economical, cultural, and educational contexts as they shape the status of Saudi preschool teachers, 2) understand the factors that might influence perceptions of teachers, status such as government initiatives or the portrayal of teachers in society, 3) present some of the controversial and challenging concerns facing Saudi preschool teachers, and 4) determine how perceptions of teacher status can be improved.

Members of the teaching profession were interviewed to assist in the conceptualization of preschool teachers' roles and status. Interviews also aimed to capture and present teachers' subjective experiences as members of the profession through semi-structured questions. In addition, some of the controversial and challenging concerns facing Saudi preschool teachers were presented through questions to identify and describe changes in perceptions of preschool teachers' status and to find out how these perceptions can be improved.

The interviews set out with a broad conception of "status" to include both objective perspectives (i.e., how teachers are viewed by other members of society) and subjective perspectives (i.e., how teachers view themselves, their work, and their profession). How do teachers compare with other professionals in terms of ratings of professional status? What comes to mind when policymakers, parents, and society as a whole are asked to think about the status of preschool teachers? Answers to these questions include their perceptions of self-esteem associated with being a teacher and their expectations of respect in how they should be treated by others. It includes teachers' conceptions of professionalism, their reasons for becoming and remaining preschool teachers, as well as examining other insights about a teaching career.

A theoretical theme is developed to guide interviews with the teachers in the sample. A total of 36 preschool teachers were interviewed gathering perceptions of their success with regard to the children they have worked with and 
key factors that have influenced their professionalism. The interviews were conducted in a non-structured way; i.e., the researcher only asked the teachers to tell their professional stories. The aim is to facilitate the reflections of teachers on their lived experiences (Barmby \& Coe, 2004). The teachers' views on professionalism emerged through the process of making sense of working situations they experienced. Interview data were coded into NVivo and then analyzed thematically. All the answers were recorded when the teachers were asked to respond to the following queries:

- $\quad$ When I start my work, I feel welcome once...

- $\quad$ I think my profession is described in particular by those characteristics/skills... because...

- In my profession, those who think about me are...

- My reasons for becoming and remaining a preschool teacher are...

- If I have considered leaving teaching, it is because...

- My perceptions of the teaching profession are...

- I feel satisfied in my profession because...

Also, teachers were asked about their perceptions of preschool education and, in particular, for their opinions

on:

- $\quad$ Recruitment

- Retention

- Teacher status

- Teacher satisfaction

- $\quad$ Future goals

\section{THEORETICAL FRAMEWORK}

\section{Geographical Context}

Saudi Arabia comprises about four-fifths of the Arabian Peninsula, a landmass constituting a distinct geographical entity. The country occupies approximately 2,250,000 square kilometers, is bounded on the north by Jordan, Iraq, and Kuwait; on the east by the Gulf, Bahrain, Qatar, and the United Arab Emirates; on the south by the Sultanate of Oman and Yemen; and on the west by the Red Sea (Al-Ameel, 2002). According to the 1974 census, the population of the country was just over 7 million; however, it has since grown dramatically. Preliminary results of the 2010 census give a total population of 27 million of which 18 million are Saudi nationals. Of the Saudi national population, $50.9 \%$ are male and $49.1 \%$ are female. Currently, it is estimated that almost half the Saudi population is under the age of 20 (MOP, 2011).

\section{Religious Context}

To appreciate the Saudi history and its political, economic, and social developments, it is necessary to realize that Islam not only permeates every aspect of a Muslim's life, but also of the country. It is beyond the scope of this paper to attempt to describe or explain Islam; nevertheless, it is true that some understanding of the spirit of Islam will help readers to see, in the correct context, the policies and regulations in terms of its efforts to benefit its own citizens. One of the most important aims of education, from preschool onwards, is to teach children about Islamic beliefs and practices.

Educational policy specifies the foundations on which education is based. These foundations are derived from Islam, a religion of knowledge and learning. They include issues of the Islamic doctrine, the values that are embraced by the Saudi society, the manner in which the youth are taught, and the pedagogical and educational goals that education strives to achieve. Among the most important foundation is:

The objective of education: understanding Islam correctly and completely, implanting and spreading the Islamic doctrine, providing students with Islamic values and instructions, acquiring knowledge along with different skills, developing constructive behavioral tendencies; advancing society economically, socially, culturally, and qualifying members in order to become useful in the construction of their society. (Educational policy article 28, MOE, 1976) 
Also, Islam, as a religion, emphasizes equal opportunities for both men and women in terms of almost all aspects of life, including education for all.

\section{Economical Context}

Since the discovery of oil, the country transformed itself from loose conglomeration desert tribes into a thriving constellation of modern cities. Oil revenues allowed for rapid development in various aspects of daily life and social changes followed economic growth. In the last 7 th Five-Year development plan, the country has given priority to enhancing education in terms of quantity and quality. Despite the low percentage of Saudi women working in the labour force in the country, as compared to advanced countries, it is the unavailability of working sectors open for Saudi women - usually limited to education and medicine - which has caused some saturation in these sectors (Bahgat, 1999). Some of the goals expressed by the Saudi 8th Five-Year plan (2005-2009) are to enlarge the scope of economic activities available for women. The increase in economic needs and the change of lifestyles have caused an increase in the number of women in the workforce. Just as in the West, Saudi women are graduating from universities at higher rates than men. Women comprise about $49 \%$ of the whole population, but the number of women participating in the labor force is about $13 \%$ of the total workforce (MOP, 2011). National Statistics confirmed that out of 1,078,554 women, 387,307 worked in education and 89,726 were employed in administrative positions. The next highest categories for the employment of women are the social services and medical services (MOP, 2011). Lately, the country's Labor Minister has been pushing for legal changes that would allow more women to work in retail jobs and factories - a sharp challenge to Saudi's sex segregation.

\section{Cultural Context}

Social and economical changes have shaped the current characteristics of Saudi society. The rise of individual/family incomes has affected the lifestyle of many Saudi families, particularly the middle and upper classes, and in this, the State has played a major role. It directs development plans by providing mortgage loans and new patterns of work, some of which are based on commerce, investments, and real estate agencies (Khalifa, 2001). Nevertheless, the drawbacks of this change are the widespread employment of foreign labor within the family, thus the family losing its influence on the socialization development of its children. The permanent presence of such labor, and the increased reliance upon it, has changed family members' obligations toward each other. In addition, there have been increasing concerns about children's health and safety as a result of staying with nannies or house cleaners in empty houses or in at-risk families. As a consequence, a rapid increase in children's services has occurred, including nurseries, day care, and preschool centers. The change in family structure from extended families to small nuclear ones has caused a shift in child-rearing and child-care practice, leading to a fundamental question: "what kind of care do children receive, and from whom?" The answer is that there are simply more opportunities and greater demand for child care services and preschool centers all throughout Saudi Arabia (Gahwaji, 2006).

\section{Educational Perspective}

Saudi Arabia has a literacy rate of about 62\%, which is the lowest in the Gulf nations. In Saudi Arabia, female literacy is estimated to be $50 \%$ and male at $72 \%$ (UNDP, 2003). Many scholarly sources portray women's education, since it started, as being highly valued in Saudi society (Zurbrigg, 1995). It is difficult to trace the beginnings of education for women in the country back before the union of the country in 1930 (Calvert \& Al-Shetaiwi, 2002). Before that date, education for women was mostly at home with the help of a female teacher and concerned the reciting of the Holy Qur'an as well as the principles of writing and reading (Prokop, 2003). Although education in Saudi Arabia is not obligatory, it is available to anyone who wishes to join the government schools; hence, student preferences play a part in the output of the educational system. The government does provide free, general scholarships for students (male and female) in some areas of general education and in all vocational, technical, technological, and higher education with free transportation for all females (Calvert \& Al-Shetaiwi, 2002). The number of female students increased rapidly between 1970 and 2010 as Table 1 illustrates how educational opportunities for females were built up over the years (MOE, 2010). 
Table (1): Number of Students in Saudi Arabia (1970-2010)

\begin{tabular}{|c|c|c|c|}
\hline Year & Males & Females & Total \\
\hline 1970 & 412,000 & 135,000 & 547,000 \\
\hline 1980 & 951,000 & 511,000 & $1,462,000$ \\
\hline 1990 & $1,624,000$, & $1,310,000$ & $2,934,000$ \\
\hline 2000 & $2,405,000$ & $2,369,000$ & $4,774,000$ \\
\hline 2010 & $2,536,479$ & $2,456,559$ & $4,993,038$ \\
\hline
\end{tabular}

Free compulsory education and open admissions have led to major improvements in female education. The availability and accessibility of schools, as well as the quality of their programs and human resources, have had significant effects on female educational enrolment, continuation, quality, and outcomes.

\section{Preschool Provision}

Preschool education in Saudi Arabia has a more recent history than that of general education. It is informal and includes day cares, nurseries, and preschool centers. The Children Act (2005) stressed the importance of improving training, progression and career structure, and recognizing the complexity of working with preschool children; however, it has been a concern that different training backgrounds have produced teachers with widely varied levels of awareness about their role, children's needs, and the objectives of the centers where they work. This is promoted by personal beliefs and values which influence their practice and raise many controversial and challenging concerns. The preschool enrolment rate was only $8 \%$ in 2002 and is very low compared to the number of children (MOE, 2005). Such low rates necessitate a better understanding of childcare practices at home and of children's readiness for school. This indicates that there is a demand to increase the number of preschool centers and teachers (which is low in comparison to the high number of children). At the national level, this ratio is good at one teacher for every 13 children, but when broken down into urban/rural differences, the discrepancy is found to be very high. There are more children entering preschool centers in cities and less in rural areas (UNESCO, 2004). Accurate statistics on the number of newborn babies is needed for the Ministry of Planning (MOP) to develop new preschool centers which in turn will lead to providing more opportunities for early childhood careers.

The Saudi government has emphasized education under the global slogan "Education for all" and it has devoted considerable financial resources toward that goal. The MOE budget for 1947-48 was 10 million riyal; by 195455, it was 21.6 million riyal; and by 2005-2006, it was 135 million riyal. This indicates how generous the government is when it comes to education, but unfortunately the proportion for preschool education is still being limited. In 2010 2011, there were 1,667 preschool centers as compared to the 13,628 elementary schools for boys and girls. These preschool centers served 117,653 children compared to 2,513,815 students at the elementary level (MOE, 2010).

\section{Controversial and Challenging Concerns}

Interviews with preschool teachers in the sample have highlighted that the most common reason behind their concerns is the issue of professionalism. It was apparent that teachers need to identify and access relevant, high-quality development opportunities that enable them to realize their full potential. This includes how teachers define a highstatus profession, the extent to which they consider teaching a high-status profession, and the factors that might contribute to status change. They suggested that there is a need to develop a professional standard for the key stages of professional development which involve consultation on the teaching profession's views about the key skills and qualities required of preschool teachers. Such standards will enable effective teachers to remain in the teaching profession and be rewarded academically, professionally, socially, and financially. In order to achieve a high-status career, teachers should demonstrate the capability to evaluate their practice, reflect critically upon it, and show improved professional performance that will add quality to their teaching and their practice in the classrooms.

The experience of one interviewee illustrates this well. Although Asmaa is a bright, compassionate, and a recent graduate of a degree in childhood studies, the minimum wage offered by the private preschool center would put her family of five well below the poverty level. As national attention turns to quality preschool education, Asmaa has 
just turned away from the profession. Children, society, and the profession all lose as Asmaa's teaching talents are wasted in an administrative job in a beauty salon. Although some of Asmaa's college classmates will accept the poor salary and benefits because they enjoy working with children, their patience with this low salary is often determined by marital status, lifestyle, and opportunities for better-paying jobs. But this is not just Asmaa's story; it is a national trend in the country. In addition, this phenomenon is an international trend all over the world. For instance, as many as onethird of all preschool teachers in the US leave the field annually (Hodgkinson, 2003), allowing low-quality care and untrained teachers to fill the empty space. Parents usually endure low-quality care because it is accessible and affordable, underestimating the importance of trained teachers (Epstein, 1999). The "dilemma" in preschool education, according to Barnett, (2003), is balancing affordability and accessibility with adequately trained teachers. Although each of these dimensions greatly influences the others, the compensation of those who choose careers in preschool education demands immediate attention.

Another example illustrated how teachers who work in private preschool centers have a very different view from the mothers who regard these centers as "rotating doors". Despite the teachers' training or education, starting salary is at minimum and wage increases are rare. Hours are long with many responsibilities, causing many teachers to quit shortly after being hired. Due to this high staff turnover, those who remain are often required to work with a large numbers of children. Paid vacation, emergency and sick days are not provided, and opportunities for professional development are absent. The only reason that teachers stay at these centers is that they enjoy working with children. In effect, most private centers are providing an essential service to the parents at the expense of the teachers (Mahdly, 2001). As teachers have stated, most of them who work in private centers are well-informed about the poor salaries but continue because they have a passion and aptitude for working with children. They continue despite the poor salaries because they have a desire to help children or because they enjoy the creativity of the curriculum offered in preschool (Al-Sunbul, Al-Khateeb, Metwali et al., 1998). However, the appeal of the slight rewards of preschool provision can understandably fade as neither appreciation nor financial support is achievable. Preschool teachers suffer reduced benefits until their patience or money runs out (Smithers \& Robinson, 2004).

Who else pays? When quality is compromised with poor compensation for teachers, children also pay a hefty price. They are unable to become securely attached to their teachers and to develop relationships with them. Some will pay even higher prices later, lacking developmental skills that could have been developed if consistent and wellqualified teachers had been available (Gahwaji, 2006). As trained and experienced teachers leave, they are being replaced by untrained and inexperienced personnel (Swigh, 2000). When the best teachers turn to more economically rewarding professions, and the most experienced turn away, it is the children who ultimately lose. Studies have shown a relationship between developmentally appropriate practices and early childhood teacher education (Hadeed, \& Sylva, 1995; Sylva et al., 2003). These studies suggested that preschool teachers who have a degree, or the equivalent in early childhood education (ECE), were not only more knowledgeable but also more sensitive and involved with children than those lacking this professional qualification. The reduced benefits earned by preschool teachers, however, make it difficult for them to pay for additional training or education from their own insufficient payments, although taking additional qualifications seldom results in recognition, status, or compensation (Sylva et al., 2003). Despite having research that shows a positive relationship between high qualifications and effective teaching strategies, no commitment has been made to give teachers, especially in private preschool centers, the financial support they need. Hard-working teachers apply a holistic approach when caring for children, even when forced to work under conditions that deny many of their needs. Children need sensitive, involved teachers who are educated about appropriate communication styles and developmentally appropriate practices; however, they also need teachers who are happy and satisfied, who have a sense of belonging, and whose own cultural, social, and spiritual needs are being met (Saluja, Early \& Clifford, 2000). Suitable wages, opportunities for advancement, and time off would give those who choose this profession the opportunity to develop and enjoy it. Also, it would be a more attractive choice for new students. In addition, the role of educational research in studying child development highlighted the importance of teachers' qualifications for the future of Saudi children (Otaibi \& Swailm, 2002).

Different nations have been developing a categorizing system to define the overall role profiles of workers in preschool programs. Based on data from a study that examined EU countries through the framing mechanism of training and provision, roles have emerged that reflect different cultural notions of what it means to be an early childhood professional. Preschool teachers rooted in the public sector with a prescribed framework of accountability are more likely to recognize their job as predominantly child-oriented and educational, whereas the early childhood 
pedagogues and the workers with a broader-based, socio-pedagogical training are more likely to view their profession in a wider context; i.e., child-oriented but also family- and community-oriented. These are issues around the notion of professionalism. The different role typologies would seem to suggest that what counts as professional knowledge or as professional action is a matter of interpretation, depending on the particular cultural discourse used to define and evaluate these concepts (Oberhuemer, 1998).

In light of concerns about the declining status of preschool teachers, as illustrated by the data collected for this study and by the difficulties of employment and retention, the rankings of preschool teachers in public surveys administered by the Ministry of Education were relatively low compared to other teaching jobs (MOE, 2002). "Professional" development implies expertise, pursuit of advanced training, and mastery of an evolving knowledge base. Preschool teachers in Saudi Arabia have historically struggled for recognition of their qualifications, particularly if they teach in child care or less formal playgroups. Data implied that almost all preschool teachers in the sample wondered if their expertise was valued and recognized by the parents and policymakers who pressure them to provide quality care and education for children. Unfortunately, but as expected, those educators who experience the fluctuations of reform efforts may be tempted to ignore important aspects of the current emphasis on accountability.

On the other hand, preschool centers have the challenge of attending to the population's increasing diversity in terms of language, needs, culture, and poverty, as well as including children with special needs. Unfortunately, not all preschool teachers have the necessary qualifications or training to meet these challenges. Even though research shows that teacher preparation is correlated with teacher quality (Arnett \& Polkinghorne, 2010), the level of education of Saudi preschool teachers varies widely, from high school diplomas to master's degrees. A study by Hamdan (2005) indicated that $56 \%$ of preschool teachers in public centers are college graduates, while $76 \%$ of that percentage is not specialized in ECE. Alternatively, $78 \%$ of preschool teachers in private centers are holders of high school diplomas only, which points to the varied level of teacher qualifications between public and private centers. Currently, the MOE in Saudi Arabia has no specific regulations for workers in preschool centers; but teachers who work in public centers are required to attend a comprehensive training program aimed toward giving in-service practical information on how to implement the national curriculum for preschool provision. The program is based on the participatory self-directed methodology through which knowledge is gained by experiential learning. The trainers in these centers are experienced Saudi teachers who have received training for more than two years under qualified consultants to become professional trainers in the field of ECE (Swigh, 2000). The teachers in the sample indicated the importance of acquiring a certificate or a degree, which is not a proof/guarantee of a better salary or benefits, but at least provides them with greater opportunity and efficacy in line with their qualifications. Thus, qualified teachers gain improved status on the personal level compared to unqualified ones, which points to the need for more educational and professional development programs in preschool provision.

Professional status depends on "society's valuing" of the capability, role, and overall contribution of a particular profession to an individual and societal well-being. Professions that have attained "professional status" share a common set of characteristics, including a high level of education and training, a strong ideal of public service with an enforced professional code of conduct, and high levels of respect from the society at large (Spears, Gould, \& Lee, 2000). The Saudi preschool teachers in most private centers are semi-professionals mainly because of their relatively low levels of education and training versus that of other professions, such as doctors, engineers and nurses. Nevertheless, teaching is the most accepted profession for women among university and high school graduates because it is in accordance with Saudi's sex segregation.

Increasing hours of work, larger class sizes, more subjects, and constantly changing curricula are cited as major de-motivators in many countries. What is expected from teachers (the 'social contract') is not pitched at a realistic level in many countries given material rewards, workloads, and work and living environments. In many countries, teachers are being asked to take on more responsibilities, including counseling and community development.

There is very little information on staff retention in the field of education in Saudi Arabia. There are four types of teacher turnover: departures of teachers at the school level, movements of teachers between public and private schools, teacher upgrading to administrative positions, and teachers leaving the profession due to other jobs. Teacher retention at the school level is a combination of attrition (through long-term illness and death, resignation, and retirement) and transfers (lateral, promotion, study leave). The main concern is the high rate of transfers of teachers 
between schools rather than attrition by itself. There is a trend of discontinuity that often characterizes teacher turnover in preschool centers (Hamdan, 2005); however, the lack of alternative employment opportunities keeps occupational attrition rates low in Saudi Arabia. This is especially the case for preschool teachers who lack the education and qualifications to be particularly valuable in the public sector.

Several research studies in Saudi Arabia investigated the issue of teachers' education and training and concluded that there is massive need for in-service training resources and programs for preschool teachers (Al-Ameel, 2002; Al-Noaim, 1996; Mahdly, 2001). Even with rapid expansion of innovative programs and new colleges for Early Childhood Education (ECE) in the country, there is currently a lack of qualified preschool teachers to fill in the spaces provided by preschool providers (Otaibi \& Swailm, 2002).

One of the challenges facing preschool education nowadays is the pressure of preparing children for elementary schools and enhancing the programs' focus on supporting children's literacy and numeracy skills. This view is supported greatly by parents, which explains the high numbers of children attending private centers. But if these beliefs were acknowledged by the government, their implications would require much larger investments in facilities and teacher preparation.

As reported in the interview data, participants' decisions to teach are not influenced by perceptions of the teacher's status except insofar as they are interpreted directly in terms of salaries, which is the norm for students considering a profession as a teacher. Those already involved in teaching stated that their decisions were based mostly on essential motivations related to wanting to work with children, to contribute to society and to do a job of which they feel proud. They reported often being encouraged by teachers who themselves enjoyed their work. Responses showed that their decisions to teach were not necessarily influenced by wanting a high-status position, a profession with a good image, or the need to be respected by the general public.

Rather than status, the overwhelming message from this study is that the workload of Saudi preschool teachers is high and their self-image is low. The challenge for those responsible for recruitment is to attract wellqualified candidates in the face of lessening popularity relative to other more respected and well-paid professions and, as indicated by the data of this study, in spite of teachers themselves talking down the profession. Also, the data showed that teachers do not leave teaching, nor do they choose to stay in teaching because of its perceived status. The most overwhelming issue related to causing teachers to consider leaving the profession, according to teacher responses, is the workload associated with change, the decline in children's behavior and the degree to which teachers feel underestimated by the parents and by society in general (Barmby, 2006).

While generally positive and satisfied with the influence they are having over children's development, behavior and attitudes within the preschool provision, teachers are less than positive about working conditions. Noticeable respect from others is a retention risk as teachers report a build-up of lack of respect - from the policymakers who impose changes on them, even when teachers advise that changes are too much too fast; from children's misbehavior; from parents who have impracticable expectations; and from society, in general, who seem to hold them responsible for improving the education crisis.

Most teachers reported that they love the core aspect of their work with a passion. Working with children, being involved in their learning, and feeling a sense of doing a socially useful job reflect intrinsic satisfiers which are very strong; however, it is evident that teachers' commitment to their work can be potentially worn away by factors such as support at the school; relationships with parents, colleagues, and children; opportunities for professional development; and salary and additional compensation for taking on more duties. However, despite the workload, the stress, the challenging children, the low salary, and the fact that many teachers may speak of retention, most stated they do not really intend to retire. From one perspective, this is a positive outcome; however, there is another side to the retention challenge. There is evidence from this study that many teachers are no longer passionate about their work and are staying in teaching because they see no alternative or because the pay and conditions (including the holidays) are more secure or better than they might get elsewhere.

Teachers' responses revealed that, overall, a desire to work with children, to help children get a good start in life, and to gain personal fulfillment from a job in which teachers could feel proud were the most important reasons for 
teachers to stay in the teaching profession. The status of teaching, the attractive image of teaching, and the desire to be respected by society were all insignificant to the teachers.

\section{RECOMMENDATIONS FOR IMPROVEMENTS}

Workers in preschool centers have traditionally been seen as caregivers rather than as teachers. The movement toward professionalism of the ECE field requires attention to practical issues in order to raise the low status of preschool teachers in the field of education and in society overall. This suggests credentials for all preschool teachers and staff, as well as preparing all professionals in the field to be competent/experts in ECE, while enlightening society that preschool education is an essential element of life with corresponding practice based on scientific research.

Another controversial issue is lack of accurate information on the different components of preschool provision. Current official data include mostly public preschool centers and the children who attend them. Data on private, non-profit, and home care are incomplete and irregular. Recommendations include developing a complete data set on preschool provision that takes account of children, teachers, and various centers.

Lack of adequate standards for early childhood teacher preparation programs is an added challenge for preschool teachers in Saudi Arabia. This proposes establishing greater portability of teaching credentials across universities and higher education programs. Such proposals could be achieved by creating shared content, concepts, and terminology; shared meanings; and shared sense of purpose within the preschool provision. Furthermore, professional preparation and certification of preschool teachers should be created separate from the general teaching certificate.

Lastly, one of the major challenges and concerns is that preschool teachers' retention rates are among the lowest in the country, as are their salaries and compensation. This concern suggests the importance of conducting more research on the reasons behind preschool teachers' turnover and the characteristics of successful retention programs. This suggestion also has policy implications for the government in their quest to improve the quality of preschool education; namely, to increase preschool teacher pay, especially at private preschool centers, to equal that of teachers at the elementary level.

\section{AUTHOR INFORMATION}

Dr. Nahla Gahwaji, Vice Dean of Home Economics and Assistant Professor at the Childhood Studies department at King Abdulaziz University, acquired her PhD from the University of Exeter in Early Childhood Education in 2006. Her primary teaching focus is in graduate-level courses on leadership, professional development, and quality control management. She has authored various articles in the field of ICT in preschool education and participated as a presenter for various local and international conferences. She is a member of the board of trustees of the Arab Council for Childhood and Development (ACCD). E-mail: ngahwaji@kau.edu.sa

\section{REFRENCES}

1. Al-Ameel, H. (2002). The effects of different types of preschool curricula on some aspects of children's experience and development in Saudi Arabia. PhD Thesis, School of Social Science, University of Wales, Cardiff, UK.

2. AL-Noaim, W. (1996). The skills needed for pre-school teachers in Saudi Arabia and in Kuwait. Master's Degree Thesis. King Saud University, Education College.

3. Al-Sunbul, A., Al-Khateeb, M., Metwali, M., \& Nour-Deen, M. (1998). Educational system in Saudi Arabia. Riyadh: Al-Kheraiji for Publishing and Distribution.

4. Arnett, S., \& Polkinghorne,W. (2010) Job dissatisfaction: a factor in maintaining a highly qualified family and consumers sciences teacher workforce, Online Journal of Workforce Education and Development Volume IV, Issue 4 - Fall 2010

5. Bahgat, G. (1999). Education in the Gulf Monarchies: Retrospect and Prospect, International Review of Education, 45(2). 
6. Barmby, P. (2006) 'Improving teacher recruitment and retention: the importance of workload and pupil behavior', Educational research. 48 (3), pp. 247-265.

7. Barmby, P., \& Coe, R. (2004) Evaluation of the Repayment of Teachers" Loans Scheme (Nottingham, DfES)

8. Barnett, W. (2003). Low wages = low quality: Solving the real preschool teacher crisis. NIEER Policy Brief. Retrieved Jan 15, 2012, from http:// nieer.org/resources/factsheets/3.pdf

9. Bartley, S., \& Sneed, T. (2004). A profile of family and consumer sciences teachers. Journal of Family and Consumer Sciences Education, 96(1), 83-88.

10. Calvert, J., \& Al-Shetaiwi, A. (2002). Exploring the mismatch between skills and jobs for women in Saudi Arabia in technical and vocational areas: The views of Saudi Arabian private sector business managers. International Journal of Training and Development, 6, 2.

11. Epstein, A. (1999). Pathways to quality in Head Start, public school, and private non-profit early childhood programs. Journal of Research in Childhood Education, 13(2), 101-119.

12. Gahwaji, N. (2006). Designing a Tool for Evaluating the Quality of Preschool Education in Saudi Arabia. $\mathrm{PhD}$ Thesis, School of Education and Lifelong Learning, University of Exeter, Exeter, UK.

13. Gerrard, T. (2004). Please, sir, can we have some respect? The New Zealand Herald.

14. Hadeed, J., \& Sylva, K. (1995). Does quality make a difference in the preschool experience in Bahrain? the European Conference on the Quality of Early Childhood Education. Paris, France.

15. Hamdan, A. (2005). Women and education in Saudi Arabia: Challenges and achievements. International Education Journal, 6(1), 42-64.

16. Hodgkinson, H. (2003). Leaving too many children behind: A demographer's view on the neglect of America's youngest children. Washington, DC: Institute for Educational Leadership.

17. Johnson, S., Berg, J., \& Donaldson, M. (2005). Who stays in teaching and why: A review of the literature on teacher retention. The project on the next generation of teaching, Harvard Graduate School of Education. Available from: www.gse.harvard.edu/ ngt

18. Khalifa, H. (2001). Changing childhood in Saudi Arabia: A historical comparative study of three female generations. PhD Thesis. Hull University, UK.

19. Keller, B. (2003). Question of teacher turnover sparks research interest. Education Week 22 (33): 8.

20. Lombardi, J. (2003). Time to care: Redesigning child care to promote education, support families, and build communities. Philadelphia: Temple University Press.

21. Mahdly, S. (2001). The attitude of parents and pre-school teachers toward the direct teaching methods. Master's Degree Thesis. King Saud University, Education College, Riyadhm Saudi Arabia.

22. MOE (1976). Educational policy: Government Decree 89/A/23/03/76, Riyadh, Ministry of Education (MOE).

23. MOE (2002). In the Education Committee of Curriculum and Supervision (Ed.): Government Decree 407/A/26/09/02, Riyadh, Ministry of Education (MOE).

24. MOE (2005). In the Education Committee of Curriculum and Supervision (Ed.): Government Decree 518/A/18/06/05, Riyadh, Ministry of Education (MOE).

25. MOE (2010). In the Education Committee of Curriculum and Supervision (Ed.): Government Decree 898/A/23/06/10, Riyadh, Ministry of Education (MOE).

26. MOP (2011). Population characteristics in the kingdom of Saudi Arabia: Central department of statistics, Population and Vital Section, Riyadh, Ministry of Planning (MOP).

27. Oberhuemer, P. (1998) A European perspective on early years training, in: L. Abbott \& G. Pugh (Eds) Training to work in the early years. Developing the climbing frame (Buckingham, Philadelphia, Open University Press).

28. OFSTED (2003). Standards and Quality 2002/03, The Annual Report of Her Majesty's Chief Inspector of Schools, Office of standards in Education (OFSTED), UK.

29. Otaibi, M., \& Swailm, B. (2002). The analysis of early childhood education objectives in Saudi Arabia. The Scientific Islamic Research Journal, 24, 14-23.

30. Prokop, M. (2003). Saudi Arabia: the Politics of Education. International Affairs, 79, I, 77-89.

31. Saluja, G., Early, D., \& Clifford, R. (2000). Public school involvement in pre-kindergarten programs: A survey of states. Unpublished manuscript, University of North Carolina at Chapel Hill.

32. Scott, C., Stone, B., \& Dinham, S. (2001). "I love teaching but..." International patterns of teacher discontent. Education Policy Analysis Archives, 9(28). 
33. Smithers, A. \& Robinson, P. (2004) Teacher Turnover, Wastage and Destinations (Nottingham, DfES)

34. Spears, M., Gould, K., \& Lee, B. (2000). Who would be a teacher? A review of factors teacher retention unit: Teacher retention facts and statistics. CPS Human Resources.

35. Swigh, S. (2000). In-service training and its effect on the performance of pre-school teacher. The Arabic Gulf Journal, 67, 58-111.

36. Sylva, K., Melhuish, E., Sammons, P., Siraj-Blatchford, I., Taggart, B., \& Elliot, K. (2003). The effective provision of pre-school education (EPPE) project: Findings from the pre-school period (summary).London: University of London Institute of Education, DfES/Sure Start.

37. UNESCO (2004). Access, public investment, and equity in ECCE: The nexus in nine high-population countries: United Nations Educational Scientific and Cultural Organization (UNESCO) Policy Briefs on Early Childhood.

38. UNDP (2003) Saudi Arabia: Women in public life. In United Nations Development Programme (UNDP). Program on Governance in the Arab Region. [Online] http://www.undppogar.org/countries/saudi/gender.html [12 Jan. 2012].

39. Whitebook, M., Sakai, L., Gerber, E., \& Howes, C. (2001). Then and now: Changes in child care staffing, 1994-2000. Washington, DC: Center for the Child Care Workforce.

40. Zurbrigg, J. (1995). Unveiling Portrayals of Muslim Women: Examining Western Texts On Saudi Women. Unpublished thesis dissertation. University of Western Ontario: Canada. 
NOTES 